\title{
Clients Satisfaction About Interpersonal Communication Sessions Conducted at Primary Health Care Centers by Health Education Providers
}

\author{
* Dr. Hasoon Fadhel Abdulla \\ M.B.Ch.B, DME (Medical Education) Private Sector- Baghdad \\ Dr. Mohammed Jassem Mahmood \\ M.B.Ch.B, DME (Medical Education) Baghdad Karkh Health Directorate \\ Dr. Abdu Al Kareem Ali Hassan \\ M.B.Ch.B, DME (Medical Education) Ministry of Health, RAQ
}

\begin{abstract}
Medical interpersonal communication is a core clinical skill and an essential component as they are convincing the patient to follow medical advice. Client prefer health providers to be warm and sympathetic, listen to what they say and ask question which are precise and easily understood. All clients attending either single or in group a session of health education held at PHC centers during the study period were included in this descriptive study. It was found that the clients of age group (35-45) years were more satisfied in communications skills of the health providers reporting a mean score of $25.6 \pm 4.8(\mathrm{P}=0.02)$. Female more satisfied about health provider communication skills, competency and health provider information This difference was found to be significant $\mathrm{P}$ value $(0.01,0.02,0.01)$ respectively. Illiterate clients were more satisfied with the health provider communication skills, competency and information since they gave them high score $(26.4 \pm 4.5,7.9 \pm 1.3,10.7 \pm 1.8)$ compared to the scores given by clients with higher education $(24 \pm 5,7.3 \pm 1.6,9.7 \pm 1.9)$. This difference was found to be significant $(\mathrm{P}=0.01)$. Older female clients who have no job and with low education level were more satisfied with interpersonal communication of health education providers at $\mathrm{PHC}$ level.
\end{abstract}

Keywords: Client, Communication, PHC, Satisfaction

DOI: $10.7176 / \mathrm{JHMN} / 71-03$

Publication date: February $29^{\text {th }} 2020$

\section{Introduction}

Communication is the activity of conveying information through the exchange of thoughts or massages by speech, visual, signal, writing or behavior (Silverman et al. 2006).

Effective interpersonal communication (IPC) between health care providers and client is one of the most important elements of improving client satisfaction, compliance, health outcome, and enable client to disclose critical information about their health problems and feeling confidence in the care being provided (Nicholas et al. 1991, Buller \& Buller 1991).

doctor-patient communication is central in clinical practice, it's a core clinical skill an essential component as they are convincing the patient to follow medical advice (Boelen 1996).

Effective communication does not always occur naturally nor it's easily acquired because they often have different educational, socio-economic and cultural back-grounds. Moreover, their expectation about the health encounter may be different, or they may be faced with other problem such as lack of privacy during encounter, or time constraints due to heavy patient loads (Nicholas et al. 1991, Mason et al.1988).

It is well established that client prefer health providers to be warm and sympathetic, listen to what they say and ask question which are precise and easily understood (Jarvis et al. 2009).

Communication research have been demonstrated the need for expressive social communication contact with other to help maintain individual wellbeing and psychological health (Droge et al. 1981). There are many factors effecting effective interpersonal communication skills including; age, gender, education, ethnic origin (Dearborn et al. 2006, Jaipaul \& Rosenthal 2003).

Patient satisfaction has three components: Instrumental behavior: higher level of information-giving by the doctor, time spent in discussion of healthcare by the doctor, and greater interview length (Smith et al.1981); Affective behavior: Bensing (1991) concludes from her study that affective behavior especially nonverbal behavior: eye contact, showing interest appears to be the most important factor in determined patient's satisfaction (Bensing 1991); And age: Older patient scoring more highly and being more satisfied than young and middle-aged patient (Jaipaul \& Rosenthal 2003).

Assessment of the quality of the doctor-patient relationship are patients recall and understanding of information (Smith et al.1981), patients' compliance is also a widely used outcome, and is considered an indicator 
of the effectiveness of physician-patient communication. However, unlike patient satisfaction study results do not indicate a clear association between doctor-patient interaction and subsequent patient compliance (Ley 1989).

\section{Aim of the study}

To assess the client satisfaction toward the health provider achievement in health education. And to determine to what extent this satisfaction affected by some sociodemographic characteristics such as age, gender, level of education and job.

\section{Patients and methods}

2.1. Study group: All clients attending either single or in group a session of health education held at PHC centers during the study period, and they were willing to participate in the study were included. Thus 325 clients were involved.

\subsection{Method}

A Structured questioner was formulated by the researcher and completed through direct interview with every client. The questionnaire was in Arabic and consist of two parts:

Part I covered the sociodemographic characteristics (gender, age, educational level and occupation of the client).

Part II consist of six domains which reflect client satisfaction regarding the effectiveness of interpersonal communication of the health provider during health education session.

According to Likert scale, a score of (1-3) was given for each theme (item) reflecting client satisfaction in regard to specific communication skill, competency and information of health providers. When the response of client was "disagree" one score was given, two scores when the response was "equivocal" and three scores when the response was "agree". Then an overall total score for each main domain was calculated and accordingly a minimum and maximum scoring was ranged as the following:

1.Communication skills consists of 10 themes: the total score ranged from 10-30

2.Health provider competency consists of 3 themes: the total score ranged from 3-9

3.Health provider information consists of 4 themes: the total scores ranged from 4-12

The other three domains: time, place and the tools used in conducting the session, each being reflected in one theme so the total score was ranged from (1-3).

Further scale had been used to identify the degree of satisfaction of the clients for the achievements of the health providers in relation to different domains of interpersonal communication to be: unsatisfied, equivocal, or satisfied according to the total scores of each domain as following:

Communication skills: unsatisfied (10-14), equivocal (15-21), satisfied (22-30).

Competency: unsatisfied (3-4), equivocal (5- 6), satisfied (7-9).

Information: unsatisfied (4-6), equivocal (7-8), satisfied (9-12).

Tools, place, time: (1) unsatisfied, (>1-2) equivocal. (>2-3) satisfied.

\section{Statistical analysis}

The collected data were introduced into micro soft office excel 2010 and were analyzed using SPSS version (21). Descriptive analysis such as frequencies and percentages had been used to describe different variables, while (mean \pm SD) was calculated for the allocated scores of different domains of interpersonal communication. To compare mean scores of different variables t-test was used. Pearson linear correlation had been assessed to detect the correlation between different domains of interpersonal communication. $p$ value $\leq 0.05$ considered as the level of significance in this study.

\section{Ethical issues}

An approval of the scientific and ethical committee at Al-Kindy College of Medicine had been taken initially, then an official request for facilitation of the omission of conducting the study was delivered from Al-Kindy College of Medicine and administered to all PHC centers that included in the study. A nonverbal consent had been taken from all the participants in the study groups.

\section{Results:}

Table- 1 showed that total clients included in this study were (325), $85.5 \%$ were female and $14.5 \%$ were male. Half of the client's 161(49.5\%) were of young age group, the frequency decreases with increasing in age. The clients were closely distributed on different education levels. Only $28.6 \%$ of the clients have job whether governmental or nongovernmental while the remaining $71.4 \%$ were without job. 
Table 1: The demographic characteristics of the clients.

\begin{tabular}{|l|c|c|c|}
\hline \multicolumn{2}{|c|}{ Character } & Frequency & Percentage (\%) \\
\hline \multirow{3}{*}{ Age group } & $15-34$ & 161 & 49.5 \\
\cline { 2 - 4 } & $35-45$ & 122 & 37.6 \\
\cline { 2 - 4 } & $>45$ & 42 & 12.9 \\
\hline \multirow{3}{*}{ Eender } & Male & 47 & 14.5 \\
\cline { 2 - 4 } & Female & 278 & 85.5 \\
\cline { 2 - 4 } & Illiterate & 77 & 23.7 \\
\cline { 2 - 4 } & $<6$ years & 71 & 21.8 \\
\cline { 2 - 4 } & $6-12$ years & 93 & 28.7 \\
\hline \multirow{3}{*}{ Job } & Educated & 232 & 71.4 \\
\cline { 2 - 4 } & No job & 93 & 28.6 \\
\hline
\end{tabular}

Table-2 showed the client response toward the achievement of the health providers in: Communication skill they reported high agreement response to six themes out of the ten themes and equivocal to four themes out of ten; Client satisfaction with health provider competency was agree for all the three themes $(53.5 \%, 51.1 \%, 46.2 \%)$; Client satisfaction with health provider information was agree for two themes and equivocal for other two themes. Most of clients $69.2 \%$ gave equivocal response to the time spent by health provider in the communication session. While $71.4,76 \%$ of the clients were agreed and satisfied with the place and the tools prepared for the health education sessions respectively.

Table 2: Domains to assess clients satisfaction about interpersonal communication with health providers

\begin{tabular}{|c|c|c|c|c|c|c|}
\hline \multirow[b]{2}{*}{ Domains } & \multicolumn{2}{|c|}{ Disagree } & \multicolumn{2}{|c|}{ Equivocal } & \multicolumn{2}{|c|}{ Agree } \\
\hline & $\mathbf{n}$ & $\%$ & n & $\%$ & $\mathbf{n}$ & $\%$ \\
\hline \multicolumn{7}{|l|}{ Communication Skill } \\
\hline 1. Greet me in a way that made me feel comfortable & 2 & 0.6 & 134 & 41.2 & 189 & 58.2 \\
\hline 2. treated me with respect. & 0 & 0 & 54 & 16.6 & 271 & 83.4 \\
\hline 3. Treat me in a friendly manner. & 13 & 4.0 & 163 & 50.2 & 149 & 45.8 \\
\hline 4. Showed interest in idea about my health. & 27 & 8.3 & 110 & 33.8 & 188 & 57.8 \\
\hline 5. Talk in term I could understand & 27 & 8.3 & 30 & 9.2 & 268 & 82.5 \\
\hline 6. Let me give my feedback & 36 & 11.1 & 167 & 51.4 & 122 & 37.5 \\
\hline 7. The health provider concerned about what I tell him & 31 & 9.5 & 133 & 40.9 & 161 & 49.5 \\
\hline 8. Encourage me to ask question. & 69 & 21.2 & 134 & 41.2 & 122 & 37.5 \\
\hline 9. Involve me in the conversion. & 45 & 13.8 & 148 & 45.5 & 132 & 40.6 \\
\hline 10. Show me care & 34 & 10.5 & 124 & 38.2 & 167 & 51.4 \\
\hline \multicolumn{7}{|l|}{ COMPETENCY } \\
\hline 1. Health provider well competent and well trained. & 33 & 10.2 & 118 & 36.3 & 174 & 53.5 \\
\hline 2. Give demonstration about the subject & 35 & 10.8 & 140 & 43.1 & 150 & 46.2 \\
\hline 3. The subject is related to my health problem. & 1 & 0.3 & 158 & 48.6 & 166 & 51.1 \\
\hline \multicolumn{7}{|l|}{ Health provider information } \\
\hline 1. Understand my main health concern. & 1 & 0.3 & 160 & 49.2 & 164 & 50.5 \\
\hline 2. Gave me as much information I wanted. & 39 & 12 & 127 & 39.1 & 159 & 48.9 \\
\hline 3. Checked to be sure I understand everything. & 51 & 15.7 & 146 & 44.9 & 128 & 39.4 \\
\hline 4. The information are applicable & 1 & 0.3 & 50 & 15.4 & 274 & 84.3 \\
\hline \multicolumn{7}{|l|}{ Health provider Time } \\
\hline 1. Spend time was enough. & 38 & 11.7 & 225 & 69.2 & 62 & 19.1 \\
\hline \multicolumn{7}{|l|}{ Place } \\
\hline 1. The place is appropriate, wide, clean, calm. & 0 & 0 & 93 & 28.6 & 232 & 71.4 \\
\hline \multicolumn{7}{|l|}{ Tools } \\
\hline 1. available tools (picture, chart, video, folder). & 0 & 0 & 78 & 24 & 247 & 76 \\
\hline
\end{tabular}

Table 3 was constructed to examine the association between age of clients and satisfaction toward the main domains of the health provider communication skills, competency and information. It was found that the clients of age group (35-45) years were more satisfied in communications skills of the health providers reporting a mean score of $25.6 \pm 4.8(\mathrm{P}=0.02)$, while client of older age groups $\geq 45$ were more satisfied in competency and information of the health providers giving mean score of $6.7 \pm 1.5,10.4 \pm 1.7$ but no significant differences in between the three age groups $(\mathrm{P}=0.4)(\mathrm{P}=0.1)$ respectively. Again, no significant differences had been found in other domain of interpersonal communication, related to time, place and tool. 
Table 3: The client perception of achievement of the health provider in interpersonal communication according to their age

\begin{tabular}{|c|c|c|c|c|c|c|c|}
\hline \multirow[b]{2}{*}{ Domains } & \multicolumn{2}{|c|}{$15-34(n=161)$} & \multicolumn{2}{|c|}{$35-45(n=122)$} & \multicolumn{2}{|c|}{$>45(n=42)$} & \multirow[b]{2}{*}{$\begin{array}{c}\mathrm{P}- \\
\text { value }\end{array}$} \\
\hline & $\begin{array}{l}\text { Mean } \\
\text { scores }\end{array}$ & SD & $\begin{array}{l}\text { Mean } \\
\text { scores }\end{array}$ & SD & $\begin{array}{l}\text { Mean } \\
\text { scores }\end{array}$ & $\mathrm{SD}$ & \\
\hline $\begin{array}{l}\text { Health provider communication } \\
\text { skill }\end{array}$ & 23.8 & 5.4 & 25.6 & 4.8 & 24.8 & 5.1 & 0.02 \\
\hline Health provider competency & 7.3 & 1.7 & 7.2 & 1.5 & 7.6 & 1.5 & 0.4 \\
\hline Health provider information & 9.8 & 2 & 10 & 1.9 & 10.4 & 1.7 & 0.1 \\
\hline Time & 2.1 & 0.6 & 2.1 & 0.5 & 2.1 & 0.5 & 0.5 \\
\hline Place & 2.7 & 0.5 & 2.7 & 0.5 & 2.8 & 0.4 & 0.6 \\
\hline Tools & 2.8 & 0.4 & 2.8 & 0.4 & 2.8 & 0.4 & 0.5 \\
\hline
\end{tabular}

Female appeared more satisfied about health provider communication skills, competency and health provider information since they reported higher mean scores $(24.9 \pm 5,7.4 \pm 1.5,10 \pm 1.9)$ than the mean score reported by male $(22.7 \pm 6.2,6.8 \pm 1.9,9.3 \pm 1.9)$. This difference was found to be significant (P-value $0.01,0.02,0.01$ ) respectively. There were no significant differences in their responses to time, place and tool of the health education sessions (Table-4).

Table 4: The client perception of achievement of the health provider in interpersonal communication according to their gender.

\begin{tabular}{|l|c|c|c|c|c|}
\hline \multirow{2}{*}{ Domains } & \multicolumn{2}{|c|}{ Male $(\mathrm{n}=47)$} & \multicolumn{2}{|c|}{ Female $(\mathrm{n}=278)$} & \multirow{2}{*}{ P-value } \\
\cline { 2 - 6 } & $\begin{array}{c}\text { Mean } \\
\text { score }\end{array}$ & SD & $\begin{array}{c}\text { Mean } \\
\text { score }\end{array}$ & SD & 0.01 \\
\hline Health provider communication skill & 22.7 & 6.2 & 24.9 & 5 & 0.02 \\
\hline Health provider competency & 6.8 & 1.9 & 7.4 & 1.5 & 0.01 \\
\hline Health provider information & 9.3 & 1.9 & 10 & 1.9 & 0.2 \\
\hline Time & 2.1 & 0.5 & 2.1 & 0.6 & 0.01 \\
\hline Place & 2.5 & 0.5 & 2.8 & 0.4 & 0.01 \\
\hline Tools & 2.5 & 0.5 & 2.8 & 0.4 & 0.4 \\
\hline
\end{tabular}

Table 5 revealed that illiterate clients were more satisfied with the health provider communication skills, competency and information since they gave them high score $(26.4 \pm 4.5,7.9 \pm 1.3,10.7 \pm 1.8)$ compared to the scores given by clients with higher education $(24 \pm 5,7.3 \pm 1.6,9.7 \pm 1.9)$. This difference was found to be significant $(\mathrm{P}=0.01)$. Also, there were significant differences between education level in their perception of health workers achievement for all domains except for the place.

Table 5: The clients' perception of achievement of the health provider in interpersonal communication according to the education status

\begin{tabular}{|c|c|c|c|c|c|c|c|c|c|}
\hline \multirow[b]{3}{*}{ Domains } & \multicolumn{9}{|c|}{ Education status } \\
\hline & \multicolumn{2}{|c|}{$\begin{array}{c}\text { Illiterate } \\
(\mathrm{n}=77)\end{array}$} & \multicolumn{2}{|c|}{$\begin{array}{c}<6 \text { years } \\
(\mathrm{n}=71)\end{array}$} & \multicolumn{2}{|c|}{$\begin{array}{c}6-12 \text { years } \\
(\mathrm{n}=93)\end{array}$} & \multicolumn{2}{|c|}{$\begin{array}{c}\text { Educated } \\
(\mathrm{n}=84)\end{array}$} & \multirow{2}{*}{$\begin{array}{c}\mathrm{P}- \\
\text { value }\end{array}$} \\
\hline & $\begin{array}{l}\text { Mean } \\
\text { score }\end{array}$ & SD & $\begin{array}{l}\text { Mean } \\
\text { score }\end{array}$ & SD & $\begin{array}{l}\text { Mean } \\
\text { score }\end{array}$ & SD & $\begin{array}{l}\text { Mean } \\
\text { score }\end{array}$ & $\mathrm{SD}$ & \\
\hline $\begin{array}{l}\text { Health provider } \\
\text { communication skill }\end{array}$ & 26.4 & 4.5 & 23.6 & 5.4 & 5.5 & 5.5 & 24 & 5 & 0.01 \\
\hline Health provider competency & 7.9 & 1.3 & 6.7 & 1.5 & 1.7 & 1.7 & 7.3 & 1.6 & 0.01 \\
\hline Health provider information & 10.7 & 1.8 & 9.6 & 2 & 2 & 2 & 9.7 & 1.9 & 0.01 \\
\hline Time & 2.2 & 0.6 & 2 & 0.3 & 0.6 & 0.6 & 2 & 0.6 & 0.01 \\
\hline Place & 2.8 & 0.4 & 2.6 & 0.5 & 0.5 & 0.5 & 2.7 & 0.5 & 0.2 \\
\hline Tools & 2.8 & 0.4 & 2.6 & 0.5 & 0.4 & 0.4 & 2.8 & 0.4 & 0.03 \\
\hline
\end{tabular}

According to table- 6 a significant association had been found between the clients who have job and those without job in regard to their satisfaction with the health provider communication skill, competency and information as those without job were more satisfied giving mean scores of $(25 \pm 5.1,7.4 \pm 1.6,10.1 \pm 1.9)$ which were higher than those who have job mean scores $(23.6 \pm 5.4,7.1 \pm 1.7,9.5 \pm 1.9) \quad$ P-value $(0.03,0.1,0.01)$ respectively. Beside that a significant difference had been found in between them in their perception to the time allocated for the sessions $(\mathrm{P}=0.01)$ but not other two domains place and tools. 
Table 6: The scores given by the client to reflect their perception for the achievement of the health provider in interpersonal communication according to their job

\begin{tabular}{|l|c|c|c|c|c|}
\hline \multirow{2}{*}{ Domains } & \multicolumn{2}{|c|}{ No job } & \multicolumn{2}{c|}{ Has job } & \multirow{2}{*}{ P-value } \\
\cline { 2 - 5 } & $\begin{array}{c}\text { Mean } \\
\text { sore }\end{array}$ & SD & $\begin{array}{c}\text { Mean } \\
\text { score }\end{array}$ & SD & 0.03 \\
\hline Health provider communication skill & 25 & 5.1 & 23.6 & 5.4 & 0.1 \\
\hline Health provider competency & 7.4 & 1.6 & 7.1 & 1.7 & 0.01 \\
\hline Health provider information & 10.1 & 1.9 & 9.5 & 1.9 & 0.01 \\
\hline Time & 2.1 & 0.5 & 1.9 & 0.5 & 0.3 \\
\hline Place & 2.7 & 0.4 & 2.7 & 0.5 & 0.6 \\
\hline Tools & 2.8 & 0.4 & 2.7 & 0.4 & 0.4 \\
\hline
\end{tabular}

\section{Discussion}

Patient satisfaction has been an important issue for health care. many previous studies have developed and applied patient satisfaction as a quality improvement tool for health care providers (Young et al. 2000). Patient satisfaction has become an important measurement for monitoring health care performance of health plans (Jatulis et al. 1997). This measurement has developed along with a new feature: the patient's perspective of quality of care (Hall \& Dornan 1990).

This study revealed that more than two thirds of the clients attending health education sessions, both as individual or in group, they were satisfied and agreed with most themes that constitute health provider communication skills. (treated me with respect) which reflect the write way of the health providers working at PHC centers in dealing with clients and their ability in mastering their verbal communication skills and greet the client, this was found in a study conducted by (Roter 1989).

Most of the clients in this study were satisfied with the theme (talk in a term I could understand), the choice of words by client or provider could greatly influences how well they understand each other. The medical terms used by provider to describe symptom usually confused clients, at the same time client often communicate in their dialects, accent often comprehension difficult for provider communication (Roter 1989).

The response of nearly half of the clients in this study were equivocal in relation to the themes of communication skill: (let me give my feedback) (treat me in friendly manner) (involve in conversation) (encourage to ask question), and that of information (checked to be sure I understand everything). That is why during health education session the dialogue between provider and client to be effective it should be in a two-way street where both speak and are listened to without interruption and exchange information in order to be fully understand what the other is trying to say. It was shown that most of clients not understand what they were told about their illness (Buller \& Buller 1987). According to Smith et al (1981) close physical proximity, physical immediacy (leaning forward), time spent in session were essential to increase understanding of session. it was found that good social relation such as (laughing, making jokes) were conveying interest, friendliness, honesty to client and lead to client satisfaction and better outcome (Ley 1989). The exchange of information between health provider and client in medical encounter is important since doctor need information to establish correct and benefit message for client (information-giving) and for client to know and understand what is the matter about his condition (informationseeking) when this occur in medical encounter lead to better outcome and client satisfaction (Bensing 1991).

in this study the response of $69.2 \%$ of the clients was equivocal in satisfaction with time spend in conversation which could be due to work overload, in a study done in Saudi Arabia showed that the length of consultation demonstrated the strongest association with client satisfaction (Schmid Mast et al. 2007).

Clients in this study of older age group ( $>45$ year) found to be more satisfied than younger age group with interpersonal communication of their health providers. There is no clear explanation for this age difference, but probably younger clients have higher expectations for patient-provider communication that influence the dynamics of the encounter and perceptions about their care. Age itself influence different patients in different manners to perceive similar interactions, physicians simply communicate differently with older patients. It was suggested that older patients were more readily satisfied with care due to their greater familiarity with the short comings of the health care system and being more forgiving of its inadequacies (Bower et al. 2003). According to Aday and Andersen (1974) study older populations will more likely report that health care interactions met their expectations. Younger patients placed greater emphasis on the expediency of their care and having control over their own health care. In contrast, older patients preferred continuity of care with a primary care provider who made most health care decisions for them (Jun et al. 2003).

This study showed that female client were more satisfied with the effectiveness of interpersonal communication of health provider than male, this could be related to the nature of female in utilizing any opportunity to ask questions in medical encounter or seeking for relevant information during provider-patient communication interview, or could be attributed to women's greater exposure to source of health information, beside the women's greater acceptance of help seeking role (Street et al. 2007). 
The illiterate client and those jobless which represent most of the housewives in our study were more satisfied with interpersonal communication than educated women, this might be due to the high expectation by those who are more educated, compared to the low expectation and more confidence in medical care system in low educated clients, this is supported by meta -analysis study done by Hall and Dornan which revealed greater satisfaction is associated with less education (Hall \& Dornan 1990). On the other hand, a study conducted by Ishikawa et al. (2009) found that education has been shown to be significant predictor of outcome of communication, since literacy of client express worse outcome in the process of care; empowerment and consideration of patient's desire and ability to adhere to treatment plan.

\section{Conclusions}

Most of the clients were satisfied with the effectiveness of interpersonal communication of the health education provider in relation to communication skills, competency and information. Older female clients who have no job and with low education level were more satisfied with interpersonal communication of health education providers at PHC level. Place and tools of health education unit in PHC were adequately prepared to upgrade the environment required to reach the expectation of the client. The time consumed during health education session was not enough from the client point of view.

\section{Recommendations}

Training courses and workshops in interpersonal communication are mandatory for all health workers. There is a need to increase the number of health providers included in health education unit in primary health care center.

\section{Acknowledgment}

My sincere gratitude and deepest respect go to Assistant Professor Dr. Yousif Abdul Raheem who served in multiple capacities as my teacher Mentor, high ethics and source of wisdom and clam through my study. Special thanks and respects to all the clients, the health providers and administers of PHC centers of Al Karkh Health Directorate, district of Al-Dora, AL-Elam for their tremendous cooperation.

Conflict of interest: there was no conflict of interest

\section{References}

1. Silverman, J., Kurtz, S., Draper, J. (2006). Skills for communication with patient. $2^{\text {nd }}$ ed. Radcliffe (Oxford), 2004. Chapter one pp: 7-8. Reviewed by Puntis M, Ann R Coll Surg Engl. 88(1):85-86.

2. Nicholas, DD., Heiby, JR., Hatzell, TA. (1991). The Quality Assurance Project: introducing quality improvement to primary health care in less developed countries. Quality Assurance in Health Care. 3(3):147165.

3. Buller, MK. and Buller, DB. (1991). Physicians' communication style and patient satisfaction. J Hlth Soc Behav. 28:375.

4. Boelen, C. (1996). The five-stars doctor: An asset to health care reform. World Health Organization, Geneva, Switzerland

5. Mason, JL., Barkley, SE., Kappelman, MM., Carter, DE., Beachy, WV. (1988). Evaluation of a self-instructional method for improving doctor-patient communication. J Med Educ. 63:629.

6. Jarvis, RI., Snadden, D., Ker, JS. (2009). Clinical communication: In John A. Dent Roland M. Hapden A. Practical guide for medical teacher Edinburgh, London, New York, Oxford Philadelphia St Louis Sydney Toronto 2009.

7. Droge, D., Arnston, P., Norton, R. (1981). The social support function in epilepsy self-help groups. Paper presented to the International Communication Association conference, Minneapolie, 1981.

8. Dearborn, J., Panzer, V., Burleson, J., Hornung, F., Waite, H., Into, F. (2006). Effect of gender on communication of health information to older adults. J Am Geriatr Soc 54:637-41.

9. Jaipaul, C., Rosenthal, G. (2003). Are older patients more satisfied with hospital care than younger patients. $J$ Gen Intern Med. 18:23-30.

10. Smith, CK., Polis, E. Hadac, RR. (1981). Characteristics of the initial medical interview associated with patient satisfaction and understanding. J. Family Practice.12:283-292

11. Bensing, JM. (1991). Doctor-patient communication and the quality of care. An observation study into affection and instrumental behavior in general practice Dissertation. NIVEL, Utrecht, 1991.

12. Ley, P. (1989). Communicating with patients. Improving communication, satisfaction and compliance. $J R$ Coll Gen Pract. 39(321):177.

13. Young, GJ., Meterko, M., Desai, KR. (2000). Patient satisfaction with hospital care: Effects of demographic and institutional characteristics. Med Care. 38:325-334.

14. Jatulis, DE., Bundek, NI., Legorreta, AP. (1997). Identifying predictors of satisfaction with access to medical care and quality of care. Am J Med Qual. 12:11-18 
15. Hall, JA., Dornan, MC. (1990). Patient socio demographic characteristics as predictors of satisfaction with medical care: a meta-analysis. Soc Sic Med. 26:383-392.

16. Roter, DL. (1989). Which facets of communication have strong effects on outcome-a meta-analysis. In: communicating with medical patients. Edited by Steward MA. and Roter DL. Sage Publications, Newbury Park, CA, 1989;65.

17. Buller, MK., Buller, DB. (1987). Physicians' communication style and patient satisfaction. J Health Soc Behav. 28:375.

18. Schmid Mast, M., Hall, JA., Roter, DL. (2007). Disentangling physician sex and physician communication style: their effects on patient satisfaction in a virtual medical visit. Patient Educ Couns. 68(1):16-22.

19. Bower, P., Roland, M., Campbell, J., Mead, N. (2003). Setting and standards based on patients' views on access and continuity: secondary analysis of data from the general practice assessment survey. BMJ. 326:25862.

20. Aday, LA., Andersen, R. (1974). A framework for the study of access to medical care. Health Serv Res. 9:20820

21. Jun, HP., Baerveldt, C., Olesen, F., Grol, R., Wensing, M. (2003). patient characteristics as predictor of primary health care. systematic literature analysis. Health Expect. 6:160-81

22. Street, RL., Gordon, H., Haidet, P. (2007). Physicians' communication and perceptions of patients: is it how they look, how they talk, or is it just the doctor? Soc Sci Med. 65(3):586-598.

23. Ishikawa, H., Yano, E., Fujimori, S., Kinoshita, M., Yamanouchi, T., Yoshikawa M. et al. (2009). Patient health literacy and patient-physician information exchange during a visit. Fam Pract. 26(6): 517-23 